\title{
Penerapan Model Pembelajaran Make-A Match (Mencari Pasangan) Untuk Meningkatakan Kemampuan Siswa Mata Pelajaran PKn Siswa Kelas IV SDN 1 Terong Tawah
}

\author{
H. Parsas \\ NIP. 196312311984031138 \\ SD Negeri 1 Terong Tawah \\ Email:yanti_mudayana@yahoo.com
}

\begin{abstract}
Abstrak: Penelitian ini dilatar belakangi oleh rendahnya nilai mata pelajaran PKn siswa kelas IV SDN 1 Terong Tawah. Masalah penelitian ini adalah bagaimanakah penerapan metode Penerapan model pembelajaran Make - A Match ( Mencari Pasangan ) untuk meningkatakan kemampuan siswa mata pelajaran PKn siswa kelas IV SDN 1 Terong Tawah Tahun 2017. Tujuan penelitian ini adalah untuk meningkatkan hasil belajar PKn siswa kelas IV SDN 1 Terong Tawah tahun pelajaran 2017. Penelitian ini merupakan penelitian tindakan kelas. Penelitian ini terdiri dari dua siklus, masing-masing siklus terdiri atas empat tahap yaitu, perencanaan, pelaksanaan, observasi dan refleksi. teknik pengumpulan data yang digunakan dalam penelitian adalah tes dan observasi. Faktor yang diteliti adalah faktor siswa dan faktor guru. Hasil penelitian ini menunjukkan bahwa penggunaan metode pembelajaran Make - A Match ( mencari pasangan ) untuk meningkatakan kemampuan siswa mata pelajaran PKn siswa kelas IV SDN 1 Terong Tawah Tahun 2017 hal ini ditandai dengan peningkatan ketuntasan belajar siswa dalam setiap siklus,yaitu 42,5\% untuk siklus I 77,5\%untuk siklus II Peningkatan hasil belajar siswa diukur dengan terpenuhinya ketuntasan belajar siswa secara klasikal dalam setiap siklus.
\end{abstract}

Kata kunci : Mencari Pasangan, Kemampuan Siswa

\begin{abstract}
This research is based on the low grade of Civics subject of grade 4 students of SDN 1 Terong Tawah. The problem of this research is how the application of the method of applying Make - A Match learning model to improve students' ability of Civics subject of fourth grade students of SDN 1 Terong Tawah Year 2017. The purpose of this study is to improve the learning outcomes of fourth grade students of SDN 1 Terong Tawah year 2017. This research is a classroom action research. This study consists of two cycles, each cycle consists of four stages namely,
\end{abstract}


planning, implementation, observation and reflection. data collection techniques used in the study are test and observation. Factors studied were student factors and teacher factors. The results of this study indicate that the use of Make-A Match learning method to increase the students 'ability of Civics subjects of fourth grade students of SDN 1 Terong Tawah Year 2017 is marked by the improvement of students' learning mastery in every cycle, that is $42.5 \%$ for cycle I $77.5 \%$ for cycle II Improvement of student learning outcomes is measured by the completion of student learning completeness in a classical manner in each cycle.

\section{Keywords: Make - A Match, Student Ability.}

\section{Pendahuluan}

Penopang dari tumbuh dan berkembangnya kehidupan berbangsa dan bernegara adalah melalui peningkatan tingkat kecerdasan warga negara (Civic Intlegensi), mengembangkan dimensi spiritual dan tanggung jawab warga negara (Civic Responsibility) dan parsitipasi warga negara dalam memajukan bangsanya (Civic participation).

Guru mempersiapkan generasi penerus bangsa seperti yang diinginkan diatas peran pendidikan dini sangat vital, karena dengan pendidikan sedini mungkin akan penanaman sikap berbangsa dan bernegara yang baik akan menjadi pondasi utama dari perilaku generasi dimasa yang akan datang.

Ditinjau dari segi keberhasilan pembelajarannya, pembelajaran mata pelajaran Pendidikan Kewarganegaraan diharapkan mampu membekali siswa dalampengetahuan dan ketrampilan intelektual yang memadai serta pengalaman praktis agar memiliki kompetensi serta efektifitas dalam berpartisipasi. Ada dua hal yang perlu mendapat perhatian guru dalam mempersiapkan pembelajaran PKn yakni : bekal pengetahuan materi pembelajaran dan metode atau pendekatan pembelajaran.

Materi PKn dalam paradigma baru dikembangkan dalam bentuk standar nasional adalah PKn yang pelaksanaannya berprinsip pada implementasi kurikulum yang terdesentralisasi. Ada empat isi pokok pendidikan kewarganegaraan, yaitu :

1. Kemampuan dasar dan kemampuan kewarganegaraan sebagai sasaran pembentukan 
2. Standar materi kewarganegaraan sebagai muatan kurikulum dan pembelajaran.

3. Indikator pencapaian sebagai kriteria keberhasilan pencapaian kemampuan.

4. Rambu - rambu umum pembelajaran sebagai rujukan alternatif bagi para guru

Pembelajaran mata pelajaran Pendidikan Kewarganegaraan dengan paradigma yang baru bertumpu pada kemampuan dasar kewarganegaraan (Civic Competence) untuk semua jenjang, sering kali guru dihadapkan pada kesulitan akan media dan model pembelajaran yang diperlukan dalam proses pembelajaran. Hal ini mengingat pelajaran PKn sangat lekat dengan pengembangan sikap dan perilaku siswa. Atau dengan kata lain muara dari pembelajaran PKn pada sekolah dasar bermuara pada aspek aktif siswa.

Inilah yang menjadi tantangan guru, agar mampu menghadirkan proses pembelajaran mata pelajaran PKn yang menyenangkan dan mampu menarik perhatian bagi siswa dalam belajar.

Dalam kegiatan pembelajaran mata pelajaran PKn kelas IV semester II dengan kompetensi dasar : Mengidentifikasikan budaya Indonesia yang pernah tampil dalam misi kebudayaan Internasional yang peneliti lakukan ternyata mengalami kesulitan.

Dari hasil pembelajaran yang dilakukan peneliti, ternyata cara dan kegiatan dalam pembelajaran yang dilakukan untuk mata pelajaran Pendidikan kewarganegaraan di kelas IV dengan kompetensi dasar Mengidentifikasikan budaya Indonesia yang pernah tampil dalam misi kebudayaan Internasional menggunakan strategi pembelajaran ceramah dan tanya jawab masih kurang memenuhi sasaran.

\section{Metode}

Penelitian ini merupakan penelitian Tindakan Kelas (PTK) yaitu suatu pencermatan terhadap kegiatan belajar berupa sebuah tindakan, yang sengaja dimunculkan dan terjadi dalam sebuah kelas secara bersama. Tindakan tersebut diberikan oleh guru atau dengan arahan dari guru yang dilakukan oleh siswa. Kemudian melaksanakan empat tahapan dalam melaksanaka Penelitian Tindakan Kelas (PTK) yang diantaranya, perencanaan, pelaksanaan, pengamatan, refleksi. Dalam penelitian ini akan dilakukan penelitian tentang Penerapan Model 
Pembelajaran Make-A Match (Mencari Pasangan)Untuk Meningkatakan Kemampuan Siswa kelas IV SDN 1 Terong Tawah Kec. Labuapi Kabupaten Lombok Barat. Kegiatan PTK ini dirancang dan dilaksanakan dalam 2 siklus, masing-masing siklus 1 kali pertemuan. Sumber data PTK ini yaitu guru, siswa, data dokumen dan catatan lapangan. Jenis data yang akan digunakan yaitu data kualitatif dan kuantitatif. Teknik pengumpulan data yang dilakukan dalam penelitian ini adalah observasi, wawancara, angket, dokumentasi, tes, dan catatan lapangan.

\section{Hasil Penelitian}

Nilai tes formatif PKn dengan materi Mengidentifikasi budaya Indonesia yang pernah tampil dalam misi kebudayaan Internasional kurang memuaskan. Hasil tersebut dapat dilihat pada tabel dibawah ini :

Tabel I

\section{Hasil Tes Formatif Pembelajaran Awal MaPel PKn}

\begin{tabular}{|c|l|c|}
\hline No & \multicolumn{1}{|c|}{ Indikator } & Keterangan \\
\hline 1 & Nilai terendah & 20 \\
\hline 2 & Nilai tertinggi & 100 \\
\hline 3 & Jumlah nilai & 2400 \\
\hline 4 & Rata - rata nilai tes formatif & 60 \\
\hline 5 & Banyaknya peserta didik yang mendapat nilai $>75$ & 11 \\
\hline 6 & $\begin{array}{l}\text { Banyaknya prosentase peserta didik yang mendapat nilai }> \\
\end{array}$ & $72,5 \%$ \\
\hline 7 & 75 & 29 \\
\hline 8 & $\begin{array}{l}\text { Banyaknya prosentase peserta didik yang mendapat nilai }< \\
75\end{array}$ & $27,5 \%$ \\
\hline
\end{tabular}

Dari tabel diatas dilihat banyaknya peserta didik yang mendapat nilai 75 ke atas hanya 11 anak, sedangkan yang mendapat nilai kurang dari 75 ada 29 anak. 
Tabel II

Sebaran Hasil Tes Formatif Pembelajaran Awal MaPel PKn

\begin{tabular}{|c|c|c|}
\hline No & Rentang nilai & Jumlah siswa \\
\hline 1 & $0-10$ & - \\
\hline 2 & $11-20$ & 2 \\
\hline 3 & $21-30$ & - \\
\hline 4 & $31-40$ & 4 \\
\hline 5 & $41-50$ & - \\
\hline 6 & $51-60$ & - \\
\hline 7 & $61-70$ & 6 \\
\hline 8 & $71-80$ & - \\
\hline 9 & $81-90$ & 5 \\
\hline 10 & $91-100$ & \\
\hline
\end{tabular}

Dari tabel diatas diperoleh gambaran mengenai sebaran nilai tes formatif pembelajaran awal secara terperinci. Sebaran nilai 40 peserta didik pada rentang nilai 11 - 20 ada 2 anak, 31 - 40 ada 4 anak, 51 - 60 ada 23 anak, 71 - 80 ada 6 anak dan $91-100$ ada 5 anak. Apabila dalam bentuk grafik adalah :

\section{Grafik 1}

\section{Grafik Hasil Tes Formatif Pembelajaran Awal Mata Pelajaran PKn}

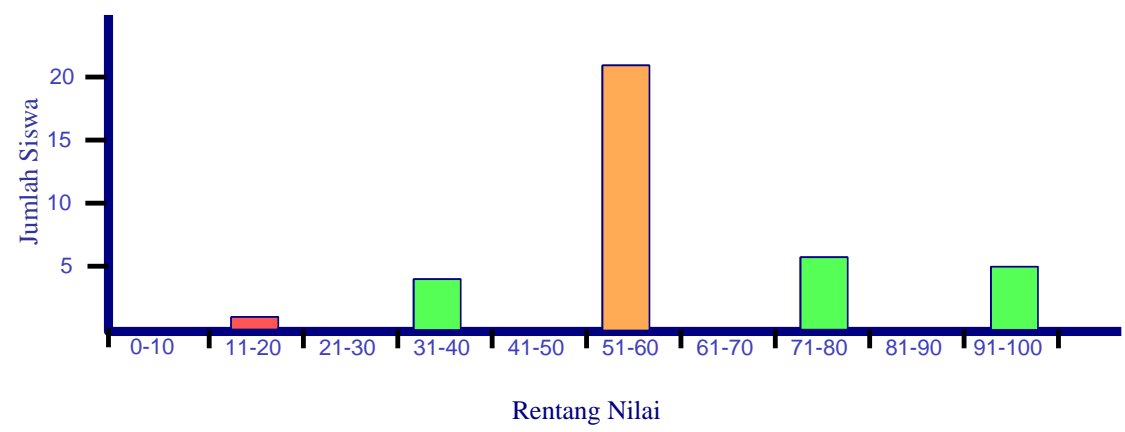

Melihat hasil tes formatif yang berada di bawah rata - rata 75, maka peneliti memutuskan untuk mengadakan perbaikan pembelajaran pada siklus I 


\section{Siklus I}

Pelaksanaan pembelajaran siklus 1. Pada perbaikan pembelajaran ini peneliti bertindak sebagai guru dan teman sejawat bertindak sebagai pengamat peneliti. Dengan bantuan teman sejawat, peneliti melaksanakan perbaikan pembelajaran sesuai dengan rencana langkah - langkah pembelajaran yang baik. Adapun hasil tes formatif perbaikan pembelajaran siklus 1 dapat dilihat pada tabel III.

\section{Tabel III}

\section{Hasil tes formatif perbaikan pembelajaran Siklus I MaPel PKn}

\begin{tabular}{|c|l|c|}
\hline No & \multicolumn{1}{|c|}{ Indikator } & Keterangan \\
\hline 1 & Nilai terendah & 60 \\
\hline 2 & Nilai tertinggi & 100 \\
\hline 3 & Jumlah nilai & 2920 \\
\hline 4 & Rata - rata nilai tes formatif & 73 \\
\hline 5 & Banyaknya peserta didik yang mendapat nilai $>75$ & 16 \\
\hline 6 & Banyaknya prosentase peserta didik yang mendapat nilai $>75$ & $42,5 \%$ \\
\hline 7 & Banyaknya peserta didik yang mendapat nilai <75 & 24 \\
\hline 8 & Banyaknya prosentase peserta didik yang mendapat nilai $<75$ & $57,5 \%$ \\
\hline
\end{tabular}

Dengan melihat tabel diatas, maka dapat diketahui hasil yang dicapai oleh peserta didik. Agar lebih jelas bisa dilihat pada tabel IV.

\section{Tabel IV}

\section{Sebaran hasil formatif Perbaikan Pembelajaran Siklus I MaPel PKn}

\begin{tabular}{|c|c|c|}
\hline No & Rentang nilai & Jumlah siswa \\
\hline 1 & $0-10$ & - \\
\hline 2 & $11-20$ & - \\
\hline 3 & $21-30$ & - \\
\hline 4 & $31-40$ & - \\
\hline 5 & $41-50$ & 24 \\
\hline 6 & $51-60$ & - \\
\hline 7 & $61-70$ & \\
\hline
\end{tabular}




\begin{tabular}{|c|c|c|}
\hline 8 & $71-80$ & 11 \\
\hline 9 & $81-90$ & - \\
\hline 10 & $91-100$ & 5 \\
\hline
\end{tabular}

Dari tabel diatas diperoleh gambaran mengenai sebaran nilai tes formatif pembelajaran siklus I secara terperinci. Sebaran nilai 40 peserta didik pada rentang nilai 51 - 60 ada 24 anak, 71 - 80 ada 11 anak dan 91 - 100 ada 5 anak. Apabila dalam bentuk grafik adalah :

\section{Grafik 1I}

\section{Grafik Hasil Tes Formatif Pembelajaran Awal MaPel PKn}

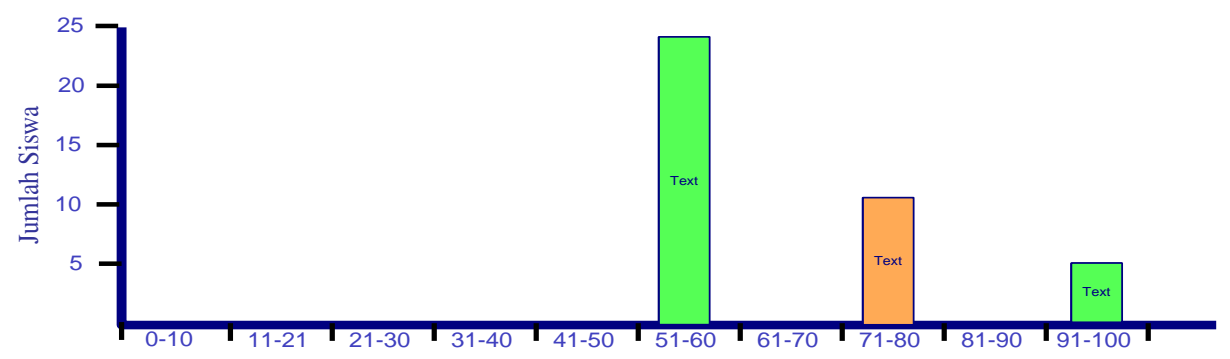

Rentang Nilai

Melihat hasil tes formatif yang berada di bawah rata - rata 75 , maka peneliti memutuskan untuk mengadakan perbaikan pembelajaran pada siklus II .

\section{Siklus II}

Pelaksanaan pembelajaran siklus II Pada perbaikan pembelajaran ini peneliti bertindak sebagai guru dan teman sejawat bertindak sebagai pengamat peneliti. Dengan bantuan teman sejawat, peneliti melaksanakan perbaikan pembelajaran sesuai dengan rencana langkah - langkah pembelajaran yang baik.Adapun hasil tes formatif perbaikan pembelajaran siklus II dapat dilihat pada tabel V.

\section{Tabel V}

\section{Hasil tes formatif perbaikan pembelajaran siklus II MaPel PKn}

\begin{tabular}{|l|l|c|}
\hline No & \multicolumn{1}{|c|}{ Indikator } & Keterangan \\
\hline 1 & Nilai terendah & 60 \\
\hline 2 & Nilai tertinggi & 100 \\
\hline 3 & Jumlah nilai & 3120 \\
\hline
\end{tabular}




\begin{tabular}{|l|l|c|}
\hline 4 & Rata - rata nilai tes formatif & 78 \\
\hline 5 & Banyaknya peserta didik yang mendapat nilai $>75$ & 30 \\
\hline 6 & $\begin{array}{l}\text { Banyaknya prosentase peserta didik yang mendapat } \\
\text { nilai }>75\end{array}$ & $77,5 \%$ \\
\hline 7 & Banyaknya peserta didik yang mendapat nilai $<75$ & 10 \\
\hline 8 & $\begin{array}{l}\text { Banyaknya prosentase peserta didik yang mendapat } \\
\text { nilai }<75\end{array}$ & $22,5 \%$ \\
\hline
\end{tabular}

Dengan melihat tabel diatas, maka dapat diketahui hasil yang dicapai oleh peserta didik. Agar lebih jelas bisa dilihat pada tabel VI

\section{Tabel VI}

\section{Sebaran hasil formatif Perbaikan Pembelajaran Siklus II Mapel PKn}

\begin{tabular}{|c|c|c|}
\hline No & Rentang Nilai & Jumlah Siswa \\
\hline 1 & $0-10$ & - \\
\hline 2 & $11-20$ & - \\
\hline 3 & $21-30$ & - \\
\hline 4 & $31-40$ & - \\
\hline 5 & $41-50$ & 9 \\
\hline 6 & $51-60$ & - \\
\hline 7 & $61-70$ & 25 \\
\hline 8 & $71-80$ & - \\
\hline 9 & $81-90$ & 6 \\
\hline 10 & $91-100$ & - \\
\hline
\end{tabular}

Dari tabel diatas diperoleh gambaran mengenai sebaran nilai tes formatif pembelajaran siklus II secara terperinci. Sebaran nilai 40 peserta didik pada rentang nilai 51 - 60 ada 9 anak, 71 - 80 ada 25 anak dan 91 - 100 ada 6 anak. Apabila dalam bentuk grafik adalah : 


\section{Grafik III}

Grafik Hasil Tes Formatif Pembelajaran Siklus II Mapel PKn

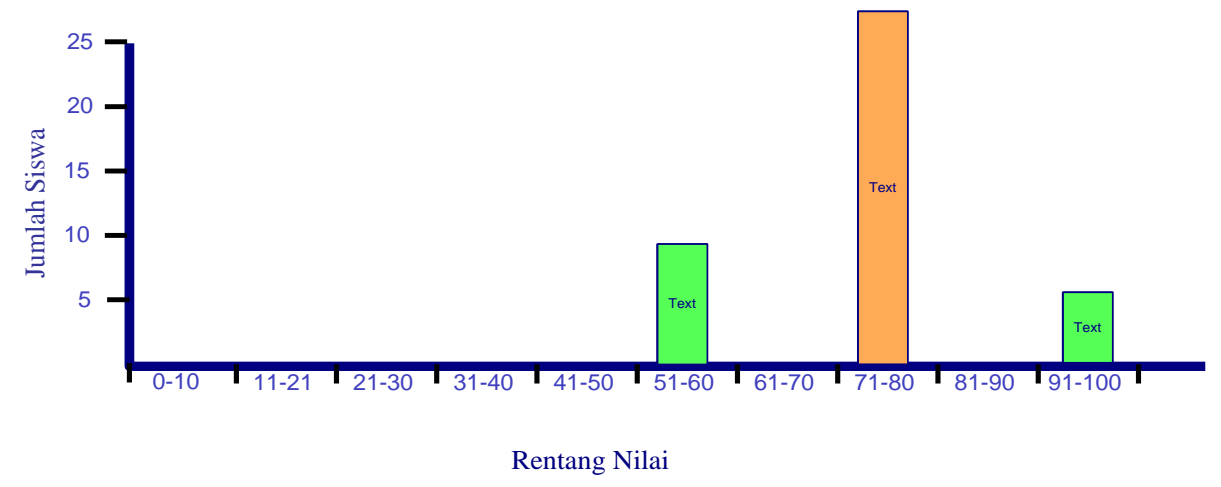

Pada pelaksanaan siklus II peneliti dan pengamat mengakui bahwa pelajaran PKn dengan menggunakan Pembelajaran Student Aktive Learning sudah baik dan prestasi belajar peserta didik meningkat mencapai ketuntasan belajar.

\section{Pembahasan}

Adapun yang dilakukan peneliti pada Siklus I ini adalah :

- Memonitor kegiatan siswa selama proses pembelajaran

- Menilai hasil belajar siswa

- Membuat analisis hasil tes formatif siswa, rata - rata kelas, tingkat ketuntasan dan prosentase ketuntasan belajar.

Dari hasil observasi serta dengan meneliti hasil belajar siswa sudah ada peningkatan pemahaman materi yang diajarkan, namun belum mencapai ketuntasan belajar, maka dengan dibantu teman sejawat, peneliti merefleksi proses pembelajaran yang dilakukan disiklus I. Adapun hasil dari refleksi siklus I adalah :

- Mengubah strategi pembelajaran yang lebih menarik dan melibatkan siswa dalam pembelajaran.

- Menggunakan model pembelajaran mencari pasangan dalam tahap pembelajaran di siklus I.

Diharapkan dengan menggunakan model pembelajaran Make-A Match atau mencari pasangan di siklus I nanti, prestasi hasil belajar siswa akan sesuai dengan harapan peneliti yaitu tercapainya ketuntasan belajar. 
Pada siklus II ini peneliti melakukan kegiatan :

- Memonitor kegiatan siswa dalam Make - A Match.

- Menilai hasil belajar siswa melalui hasil tes formatif.

Hasil dari observasi yang dilakukan peneliti dengan dibantu teman sejawat, nyatalah bahwa dengan media, strategi dan model pembelajaran yang sesuia dan menarik, menjadikan proses pembelajaran yang mengaktifkan siswa, membuat guru tertantang dan menjadi lebih kreatif, dengan sendirinya pembelajaran menjadi efektif dan menyenangkan.

Sesuai hasil observasi diatas, refleksi peneliti dalam proses perbaikan pembelajaran pada siklus II ini, peneliti merasa puas, karena hasil belajar yang diperoleh siswa sudah mencapai ketuntasan.

Dari sisi kegiatan pembelajaran, peneliti merasa tertantang untuk menerapkan media, strategi dan model pembelajaran yang lain untuk proses pembelajaran selanjutnya termasuk pada mata pelajaran yang lain. Akhirnya peneliti menyadari dalam penyampaian materi pembelajaran PKn dengan pokok materi Mengidentifikasi budaya Indonesia yang pernah tampil dalam misi kebudayaan Nasional,menggunakan model pembelajaran Make-A Match mampu meningkatkan hasil prestasi belajar siswa.

\section{Kesimpulan}

Sesuai dengan hasil penelitian yang telah dilakukan, akhirnya peneliti dapat menyimpulkan bahwa :

a. Upaya dalam melakukan kegiatan Penelitian Tindakan Kelas (PTK) dalam meneliti dan menyelidiki penyebab dari kekurang berhasilan dalam mengajar, membawa dampak yang positif dalam usaha mencapai tujuan pembelajaran di dalam kelas.

b. Pembelajaran mata pelajaran PKn pada kelas IV dengan kompetensi dasar Mengidentifikasi budaya Indonesia yang pernah tampil dalam misi kebudayaan Internasional, dengan menggunakan media pembelajaran yang beragam yang dipadukan dengan pendekatan model pendekatan Make - A Match, terbukti mampu meningkatkan minat belajar dan prestasi hasil belajar siswa kelas IV SDN I Terong Tawah. 
c. Dengan pembuatan laporan penelitian ini mampu meningkatkan pemahaman bagi peneliti akan pentingnya penelitian tindakan kelas dalam mengupayakan keberhasilan pembelajaran yang dilakukan, dan dapat menjadi umpan balik untuk pembelajaran berikutnya.

d. Penggunakan media pembelajaran yang bervariatif atau beragam akan berdaya guna bila disertai dengan skenario pembelajaran yang sesuai dengan kebutuhan dari tujuan pembelajaran yang diharapkan.

\section{Daftar Pustaka}

Andayani, dkk. 2008. Pemantapan Kemampuan Profesional. Jakarta Universitas Terbuka Anggoro, M. Toha, dkk. 2007. Metode Penelitian. Jakarta Universitas Terbuka.

BSNP. 2006. Standar Isi Kompetensi Dasar Mata Pelajaran Pendidikan Kewarganegaraan SD Kelas IV. Jakarta : Erlangga.

Djauzak Ahmad. 1994. Pedoman Proses Belajar Mengajar di Sekolah Dasar . Jakarta : Balai Pustaka.

Departemen Pendidikan dan Kebudayaan 1999. Kurikulum Pendidikan Dasar. Jakarta : Depdikbud.

Depdikbud, 2001. Kamus Besar Bahasa Indonesia. Jakarta : Balai Pustaka.

Hernawan, Asep Herry, dkk. 2008. Pengembangan Kurikulum dan Pembelajaran. Jakarta : Universitas Terbuka.

Nugroho, Sarjan Agung. 2008. Pendidikan Kewarganegaraan kelas IV SD. Jakarta : Pusat Perbukuan Departemen Pendidikan Nasional.

Tim Redaksi. 2003. Undang - Undang Dasar 1945 ( Amandemen MPR ). Jakarta : Restu Agung.

Wardani, IGK, dkk. 2007. Penelitian Tindakan Kelas. Jakarta : Universitas Terbuka.

Winataputra, Udin S,dkk. 2006. Materi dan Pembelajaran PKn SD.Jakarta : Universitas Terbuka.

Winataputra, dkk. 2004. Strategi Belajar Mengajar. Jakarta : Universitas Terbuka. 